\title{
Risicobeheersing in ziekenhuizen met Diagnose Behandel Combinaties
}

\section{Willem Peter de Ridder en Paul Nijssen}

SAMENVATTING Met ingang van 1 februari 2005 is een nieuw bekostiging- en financieringsysteem ingevoerd voor ziekenhuizen op basis van Diagnose Behandel Combinaties (DBC's). Voor ziekenhuizen leidt dit tot aanzienlijk grotere (financiële) risico's. Wij hebben het effect onderzocht van DBC's op de risicobeheersing binnen drie Nederlandse algemene ziekenhuizen. Ziekenhuisbestuurders erkennen DBC's als beheersingsmiddel, hebben de interne controle verbeterd en het toezicht geprofessionaliseerd, maar de inrichting van een gestructureerd programma voor risicobeheersing laat nog op zich wachten. Ook strategische aanpassingen van het zorgaanbod komen we slechts beperkt tegen. Het blijft de medisch specialist die beslist over de aard en duur van de behandeling.

RELEVANTIE VOOR DE PRAKTIJK De wijze van bekostiging van ziekenhuizen is aan grote veranderingen onderhevig door de invoering van DBC's die in 2005 is begonnen en minimaal tot 2009 duurt. Dit artikel geeft een tussenstand in de wijze waarop ziekenhuisbestuurders hun risicobeheersing hierop aanpassen

Dr. W.P. de Ridder is operationeel risicomanager bij AEGON en lid van de kerngroep BIV-Interne Beheersing en Informatiecontrole van de NIVRA-Nyenrode School of Accountancy \& Controlling. Drs. P.J.A. Nijssen is supervisor bij KPMG Accountants en gespecialiseerd in de gezondheidszorg.

\section{Inleiding}

Sinds 2005 zijn alle medische ingrepen in Nederland gedefinieerd en van een standaardprijs voorzien in zogenaamde Diagnose Behandel Combinaties (DBC's), die de basis vormen voor een nieuw bekostiging- en honoreringsysteem voor ziekenhuizen en medisch specialisten. Met de invoering van DBC's wordt beoogd de transparantie in het zorgaanbod te vergroten. Inzicht in de zorgvraag en de zorgprocessen moet binnen ziekenhuizen een efficiëntere bedrijfsvoering mogelijk maken en zorgverzekeraars een sterkere positie geven bij het inkopen van zorg. Transparantie is een noodzakelijke voorwaarde om te komen tot gereguleerde marktwerking en een vraaggestuurd stelsel voor de gezondheidszorg.

DBC's in zuivere vorm maken een koppeling tussen de bekostiging en de productie. Dit leidt tot aanzienlijk grotere (financiële) risico's voor ziekenhuizen en daarom mag worden verwacht dat ziekenhuisdirecties meer aandacht zullen besteden aan de beheersing van die risico's als onderdeel van een meer bedrijfseconomische manier van denken en handelen. De vraag die wij in dit artikel aan de orde stellen is of invoering van de bekostiging op basis van DBC's tot verbetering van de risicobeheersing binnen Nederlandse ziekenhuizen leidt. Daarbij moet worden onderkend dat veranderingen in de risicobeheersing niet alleen door deze instrumentele vernieuwing, maar ook door andere externe factoren, zoals de maatschappelijke druk van wachtlijsten en generieke budgetkortingen, tot stand kunnen komen.

Op basis van (internationale) literatuur over risicomanagement en vergelijkbare bekostigingssystemen in het buitenland is een conceptueel model opgebouwd van de verwachte gevolgen van DBC's voor de risicobeheersing in ziekenhuizen. Vervolgens is dit met casestudies in drie algemene ziekenhuizen empirisch onderzocht.

In Nederland kennen we verschillende categorieën 
ziekenhuizen: algemene ziekenhuizen, categoriale ziekenhuizen, universitair medische centra en privéklinieken (zelfstandige behandelcentra). Een algemeen ziekenhuis verzorgt de basis van de medisch specialistische zorg in zijn werkgebied en heeft soms ook een aantal specialistische afdelingen, zoals hartchirurgie of neurochirurgie. Categoriale ziekenhuizen zijn de zeer specialistische ziekenhuizen met één of een beperkt aantal specialismen, zoals het Oogziekenhuis in Rotterdam. De universitair medische centra leveren de complexe medisch specialistische zorg en vervullen daarnaast een belangrijke opleidings- en onderzoeksfunctie. Dit onderzoek richt zich op de grootste groep, namelijk de algemene ziekenhuizen. De academische activiteiten worden vanwege het ontbreken van een direct verband met de DBC-systematiek buiten beschouwing gelaten.

Dit artikel sluit aan bij eerdere publicaties over de ziekenhuiszorg in Nederland in het MAB, onder andere in het themanummer maart 2007. Hierin beschreef Asselman (2007) het kostprijsinformatiesysteem van het AMC, gaven Groenewegen (2007) en Brandenburg (2007) inzicht in de relatie tussen ziekenhuizen en zorgverzekeraars vanuit de transactiekostentheorie en ging Vosselman (2007) in op de gevolgen van marktwerking voor de rol en autonomie van de medisch specialist. In dit artikel kiezen we het perspectief van het bestuur van een algemeen ziekenhuis, dat verantwoordelijk is voor afstemming van het zorgaanbod op de (lokale) markt en de continuïteit van de organisatie en daarvoor een proces van interne beheersing en risicomanagement in stand houdt.

De opbouw van dit artikel is als volgt. Paragraaf 2 geeft een nadere uiteenzetting van DBC's in vergelijking met de functionele bekostiging die tot 2005 van toepassing was voor ziekenhuizen. In paragraaf 3 gaan we in op de veranderingen die op basis van de literatuur over risicomanagement in ziekenhuizen mogen worden verwacht na de invoering van DBC's. Paragraaf 4 beschrijft de resultaten van de casestudies en paragraaf 5 sluit af met de conclusies.

\section{2}

\section{Bekostiging van ziekenhuizen op basis van DBC's}

Tot 2005 werden de inkomsten van ziekenhuizen wettelijk vastgesteld op basis van zogenaamde functiegerichte budgetparameters. Het budget bestond uit vergoedingen voor locatiekosten (gebouwen en installaties), beschikbaarheid in het verzorgingsgebied (op basis van het aantal inwoners in dat gebied), capaciteit (op basis van aantal bedden en specialisten) en productie (aantal opnamen en bezoeken). Het budget was deels vast vanuit de gedachte dat belangrijke kosten als personeel en gebouwen niet variëren met de productie. Voor ziekenhuizen leidde dat bij een stabiele vraag vanuit het verzorgingsgebied tot een eenvoudig en overzichtelijk budgetterings- en verantwoordingssysteem. Nadeel van het systeem van functionele bekostiging was dat het geen duidelijke koppeling kende tussen de prestaties en het budget. Door het ontbreken van financiële prikkels voor extra productie en innovatie, ontstonden wachtlijsten en werden nieuwe, efficiëntere behandelmethoden niet financieel gestimuleerd. Doordat de politiek bovendien een maximaal budget vaststelde om de kosten van de zorg binnen de perken te houden, ontstond een tekort aan de aanbodzijde in de vorm van wachtlijsten.

In de overgang naar een vraaggestuurde gezondheidszorg is bekostiging op basis van DBC's een instrument dat concurrentie tussen zorgaanbieders, bedrijfsmatige prikkels en reductie van de kosten mogelijk moet maken. Met de DBC wordt een koppeling gelegd tussen de behandeling van de patiënt en de bekostiging van het ziekenhuis. De gedachte hierachter is dat patiënten met een soortgelijke diagnose een soortgelijk behandeltraject doorlopen en daarbij gebruik maken van dezelfde diensten die dus tot dezelfde kosten leiden. Een DBC staat voor een standaard diagnose- en behandeltraject (opname, medische verrichtingen, verpleegdagen, hulpmiddelen en dergelijke), waaraan een daarvoor te claimen vergoeding gekoppeld wordt. De DBC's zijn onderverdeeld in een A- en B-segment. Voor het A-segment vindt de bekostiging door middel van een omrekening feitelijk nog plaats op basis van de voormalige functionele bekostigingsparameters. Voor het B-segment is met ingang van 1 februari 2005 de functionele bekostiging verlaten en overgegaan naar bekostiging op basis van DBC's. In 2007 is ongeveer 10 procent van alle productie van ziekenhuis en medisch specialist als B-segment aangemerkt. Hiervoor kan de Raad van Bestuur van een ziekenhuis met de zorgverzekeraars onderhandelen over de hoeveelheid en de prijs. Voor 2008 is voorzien dat het B-segment groeit tot 20 procent van de totale productie.

De invoering van DBC's ligt in lijn met ontwikkelingen in het buitenland. Onder andere ook de Verenigde Staten, het Verenigd Koninkrijk, Zweden en Nieuw-Zeeland kennen systemen waarbij sprake is van bedrijfsmatige prikkels door een koppeling tussen behandeling en bekostiging. Het Nederlandse systeem van DBC's lijkt sterk op het Amerikaanse Diagnosis Related Group / Prospective Payment System (DRG/PPS). PPS is gebaseerd op 467 productlijnen die DRG's worden genoemd. De prijzen van deze producten zijn gebaseerd op historische, gemiddelde kosten. De DRG's zijn ingedeeld naar de 23 
belangrijkste diagnosecategorieën, vergelijkbaar met de 26 Nederlandse specialismen. Voor iedere DRG of productlijn is een standaardprijs per eenheid vastgesteld die vergoed wordt door Medicare, de Amerikaanse sociale ziektekostenverzekering, onafhankelijk van de werkelijke kosten voor behandeling of geleverde producten (Chua en Preston, 1994). Groot verschil tussen de Verenigde Staten en Nederland is dat een basisverzekering in Nederland voor alle ingezetenen verplicht is en verzekeraars een acceptatieplicht hebben zonder selectiemogelijkheden. Hiermee is de beschikbaarheid van de zorg in Nederland voor de gehele bevolking door de overheid geborgd, en daarmee is de verzekeringsmarkt in Nederland fundamenteel anders dan die in de Verenigde Staten.

Door middel van DBC's wordt een koppeling gelegd tussen input en output per ziekenhuis. Het ziekenhuis kan deze koppeling in haar management control doorvoeren naar afdelingsniveau en daarmee normen stellen voor resultaten. Afwijkingen ten opzichte van de norm zijn aanleiding tot nader onderzoek en bijsturing. Dit betekent een veel grotere rol voor management control en veel meer nadruk op de kostenbeheersing in de discussie over de gezondheidszorg. In landen waar een met DBC's vergelijkbaar systeem is geïmplementeerd, is een sterke toename van (goedkopere) poliklinische zorgverlening door ziekenhuizen geconstateerd. Dit betekent dat patiëntenstromen binnen het ziekenhuis opnieuw moeten worden ingedeeld. Ook geeft ongeveer tweederde van de artsen aan patiënten sneller te ontslaan om de ligduur te verkorten. Dit heeft echter als gevolg dat de kosten van zorg aan huis sterk stijgen en zorgverplaatsing plaatsvindt van ziekenhuis naar verpleeghuis (Coddington et al., 1985; Chua en Preston, 1994).

\section{Conceptueel verwachte gevolgen van DBC's voor de beheersing in ziekenhuizen}

Op zoek naar het antwoord op de vraag of DBC's leiden tot een verbetering van de risicobeheersing in ziekenhuizen beschrijven we in deze paragraaf allereerst wat risicobeheersing voor een ziekenhuisorganisatie conceptueel zou betekenen en welke veranderingen hierin verwacht mogen worden als gevolg van de invoering van DBC's. Voor deze analyse is gebruik gemaakt van het raamwerk voor Enterprise Risk Management van COSO. Voor een beschrijving van dit model verwijzen wij naar eerdere MAB-publicaties, bijvoorbeeld Droogsma (2007) en Emanuels en De Munnik (2006). In navolging van het rapport Corporate Governance van Tabaksblat is voor zorginstellingen in 2005 de Zorgbrede Governancecode opgesteld (Brancheorganisaties Zorg, 2005). Hierin is onder meer de bepaling opgenomen dat de Raad van Bestuur verantwoordelijk is voor het beheersen van de risico's die verbonden zijn aan de activiteiten van de zorgorganisatie (het "in control" zijn) en dat de Raad van Bestuur over het interne risicobeheersingen controlesysteem verantwoording aflegt aan de Raad van Toezicht. Het COSO ERM-raamwerk biedt een leidraad om hier invulling aan te geven.

Om te beginnen moeten we vaststellen welke doelstellingen de ziekenhuisdirecties nastreven, indien sprake is van bekostiging op basis van DBC's. Wij zien wij de volgende vier doelstellingen:

1 Bevorderen van een klantgericht zorgaanbod. Onder de functionele bekostigingsystematiek werden ziekenhuizen betaald voor anwezigheid en productie volgens vastgestelde budgetparameters. In de DBCsystematiek is het voor de continuiteit van het ziekenhuis veel belangrijker geworden dat het zorgaanbod is afgestemd op de patiëntvraag.

2 Reductie van ziekenhuiskosten. Invoering van DBC's moet de effectiviteit en efficiency van de bedrijfsprocessen helpen verbeteren. Concreet moet voor 2008 een bezuiniging van 2 procent van het budget worden gerealiseerd.

3 Transparantie in de interne en externe rapportage en verantwoording. DBC's bieden de mogelijkheid tot gedetailleerde interne managementinformatie op basis waarvan de ziekenhuisdirectie sturing kan geven. Ook de externe verantwoording kan beter worden door het vergroten van het inzicht in de nota's die een ziekenhuis stuurt, waardoor deze nota's beter controleerbaar zijn voor klanten en zorgverzekeraars.

4 Voldoen aan wet- en regelgeving. Invoering van de DBC-systematiek en van een intern controlesysteem is verplicht voor alle ziekenhuizen in Nederland.

Vervolgens is de vraag door middel van welke activiteiten bovenstaande doelstellingen worden gerealiseerd. Wij hebben daartoe een systematische vergelijking gemaakt van de door COSO gesuggereerde componenten van een systeem voor risicomanagement met de situatie in ziekenhuizen. Hieruit hebben we afgeleid dat als gevolg van de invoering van DBC's voor de bekostiging van ziekenhuizen de volgende veranderingen in de beheersing bij ziekenhuizen mogen worden verwacht:

- Medisch specialisten hebben traditioneel een dominante beschikkingsmacht over de middelen van het ziekenhuis. Zij bepalen de diagnose, schrijven de 
behandelingen en medicijnen voor en bepalen de verblijfsduur in het ziekenhuis. De overgang naar een op DBC's gestuurde organisatie beïnvloedt de verhouding tussen het ziekenhuismanagement en de medisch specialist. Artsen blijven volledig verantwoordelijk voor het stellen van de diagnose en de behandeling, maar worden ook gevraagd ondernemende werknemers of economische medici te worden (Vosselman, 2007). De verdeling van de beschikbare middelen gebeurt door de markt en/of door een door de overheid aangewezen autoriteit en dwingt de ziekenhuizen tot een verschuiving van medisch professionele control naar meer financial control (Doolin, 2002).

- Invoering van DBC's dwingt ziekenhuisorganisaties tot een strategische heroriëntatie en nieuwe marketingstrategieën. De oude bekostigingssystematiek leidde tot een totaalaanbod in algemene ziekenhuizen, terwijl de DBC-systematiek leidt tot focus in het aanbod van een ziekenhuis en schaalvergroting op een beperkt aantal DBC's. Het is economisch voordeliger om enkele behandelingen vaak uit te voeren dan veel behandelingen af en toe.

- De DBC-systematiek leidt voor ziekenhuisorganisaties tot meer en grotere financiële risico's. Ziekenhuizen spelen hierop in door implementatie van een gestructureerd proces van risicomanagement, gebaseerd op bedrijfsmatige modellen. Risico's worden procesmatig in kaart gebracht en beoordeeld en leiden tot beheersingsmaatregelen.

- Eén van de mogelijke beheersingsmaatregelen om de kosten binnen te perken te houden, is de invoering van prestatieafhankelijke beloningen. Deze zetten managers en medisch specialisten aan tot efficiënte inzet van de beschikbare middelen.

- Als gevolg van de DBC-systematiek heeft het lijnmanagement veel meer stuurinformatie nodig over kostprijzen, resultaten per afdeling en doelmatigheid (nacalculatie van kostprijs en verkoopprijs). Deze informatie is alleen samen te stellen door de inzet van ICT. Dit zal naar verwachting leiden tot aanzienlijke investeringen in nieuwe managementinformatiesystemen voor financial accounting, kostprijzen en patiëntcodering (Lawrence et al., 1994).

- Facturering op basis van DBC's moet leiden tot transparante nota's, die controleerbaar zijn voor cliënten en zorgverzekeraars.

- De invoering van de DBC-bekostigingsystematiek leidt tot professionalisering van de monitoringfunctie. Dit uit zich enerzijds in de inrichting van een interne controlefunctie en anderzijds in professionalisering van het (financieel) toezicht. De Regeling 'Administratieve Organisatie en Interne Controle inzake DBC registratie en facturatie' (Nederlandse Zorgautoriteit,
2007) stelt de aanstelling van een interne controlefunctionaris verplicht. Dit moet verzekeraars meer zekerheid geven over de juiste werking van de $\mathrm{AO} / \mathrm{IC}$ en over de betrouwbaarheid van de interne informatie en de declaraties. Beheersingsmaatregelen zijn ook wenselijk ter voorkoming van 'moral hazards' zoals het opportunistische gedrag van artsen die, indien voor een bepaalde ziekte meerdere behandelingen beschikbaar zijn, de meest lucratieve kiezen in plaats van de meest efficiënte (Chua en Preston, 1994) of 'upcoding': een arts selecteert op basis van de behandeling een duurdere DBC dan feitelijk uitgevoerd (Aaron en Schwartz, 1985 en Groenewegen, 2007). De Raad van Toezicht zal naar verwachting leden krijgen met een bedrijfseconomische achtergrond in plaats van de traditionele zorg- of overheidsachtergrond.

In figuur 1 is schematisch een conceptueel model weergegeven op basis van bovenstaande analyse. Dit vormt de basis voor het empirisch onderzoek dat in de volgende paragraaf wordt beschreven.

Figuur 1 Gevolgen van de invoering van DBC's voor de beheersing van ziekenhuizen

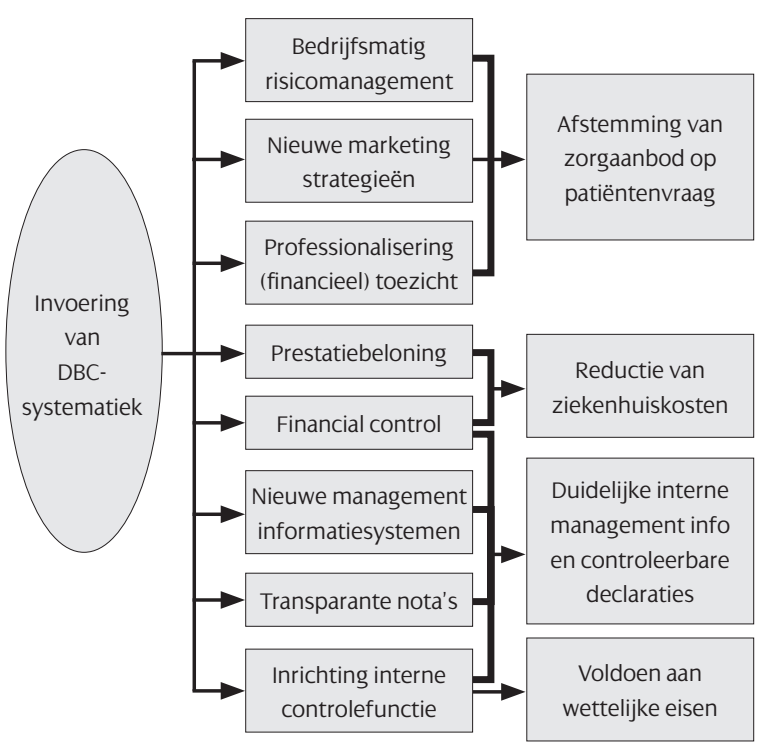

\section{Resultaten van het praktijkonderzoek}

In een drietal ziekenhuizen is door middel van casestudies empirisch onderzoek gedaan naar de veranderingen in de beheersing van de ziekenhuisorganisatie als gevolg van de introductie van DBC's. Het onderzoek heeft plaatsgevonden bij drie algemene ziekenhuizen: het Havenziekenhuis in Rotterdam, het 
Beatrixziekenhuis in Gorinchem en het Vlietland Ziekenhuis in Schiedam en Vlaardingen. Universitair medische centra zijn niet onderzocht, omdat zij naast ziekenhuiszorg ook opleidingen bieden en onderzoek doen, zouden de onderzoeksresultaten niet goed vergelijkbaar met de algemene ziekenhuizen. De drie geselecteerde ziekenhuizen hebben als gezamenlijk kenmerk ook dat zij hebben gekozen voor het aanbieden van een basis medische zorg en bewust niet voor het aanbieden van topklinische zorg. In de nabije omgeving van de drie ziekenhuizen zijn voor patiënten voldoende alternatieven aanwezig voor geplande en topklinische medische zorg. De ziekenhuizen verschillen weliswaar qua omvang, maar zijn binnen de branche relatief kleine spelers. Ze worden geconfronteerd met alle vraagstukken waarvoor een kleiner regionaal of stedelijk ziekenhuis op het gebied van risicobeheersing staat. Binnen de drie onderzochte organisaties is gesproken met de (voorzitter) Raad van Bestuur, het hoofd administratieve en economische dienst ofwel financieel manager, de interne controlefunctionaris en de bij het ziekenhuismanagement betrokken medisch specialist, bijvoorbeeld de vertegenwoordiger van de medische staf.

\section{Bedrijfsmatig risicomanagement}

De invoering van DBC's leidt tot een grotere financiële verantwoordelijkheid, waarbij de inkomsten sterker afhankelijk zijn van de productie dan voorheen. De verwachting was dat dit zou leiden tot meer gestructureerd en bedrijfsmatig risicomanagement. Dit vindt echter bij geen van de onderzochte casussen (nog) plaats. Experts onderkennen wel dat structureel risicomanagement leidt tot bewaking van de risico's die strategische doelen bedreigen, maar geven daar nog weinig gevolg aan. We hebben wel gezien dat de onderzochte ziekenhuizen bij nieuwe projecten gebruikmaken van SWOT-analyses ${ }^{1}$ en business cases om de financiële impact van beslissingen te analyseren. DBC's worden in de business cases als handig rekenmiddel gebruikt voor kostprijsberekeningen en de vertaling van productie naar geld. Risicomanagement en bewaking van de strategische doelen vindt vooral plaats in de discussies tussen Raad van Toezicht en bestuurders en tussen bestuurders en afdelingshoofden. De diepgang van deze discussies is als gevolg van budgetdruk, DBC's en generieke kortingen de afgelopen jaren duidelijk toegenomen en meer gefocust op financiële impact.

Het beperkte gebruik van bedrijfsmatige risicomodellen wordt mogelijk veroorzaakt doordat in 2007 slechts 10 procent van het ziekenhuisbudget wordt afgerekend volgens het principe van DBC's onder vrije marktwerking. Voor de overige 90 procent geldt dat afrekening plaatsvindt volgens de functionele bekostigingsystematiek, waarbij de beschikbaarheidfunctie een grote impact heeft op de omvang van het budget. Ziekenhuizen richten zich hierdoor nog steeds grotendeels op behoud van de klandizie van de op het ziekenhuis georiënteerde bevolking (adherentie).

Een relatie tussen inkomende geldstroom en risicobeheersing ligt er duidelijk: waar de inkomende geldstroom sterk afhankelijk is van wetgeving en politieke omstandigheden, is het proces van risicobeheersing sterk reactief op wetgeving en minder gericht op het analyseren van (nieuwe) markten en producten.

\section{Nieuwe marketingstrategieën}

DBC's worden door onderzochte ziekenhuizen gebruikt om de frequentie van behandelingen in hun ziekenhuis te analyseren en vervolgens te overwegen of minder frequent uitgevoerde, niet spoedeisende behandelingen moeten worden gestaakt. Dit is niet alleen een kwestie van efficiency, maar ook van kwaliteit. Als een arts slechts enkele malen per jaar een complexe behandeling uitvoert, is de vraag of hij voldoende ervaring houdt voor het goed uitvoeren ervan.

Ziekenhuizen zijn vooralsnog voorzichtig in het op grote schaal aanbieden van gunstig geprijsde DBC's. Het Havenziekenhuis heeft als enige onderzochte casus een zogenaamde liesbreukenstraat ingericht, vanwege de enorme vraag (wachtlijst) naar liesbreukbehandelingen. De ziekenhuisdirecties geven aan dat marge alleen geen goede basis vormt voor het maken van strategische keuzes, omdat voor gunstig geprijsde DBC's voldoende aanbod op den duur zal leiden tot een prijsdaling en reductie van de winstgevendheid. Twee van de drie onderzochte ziekenhuizen hebben een lokaal monopolie. Voor hen spelen de geografische factor en beschikbaarheidfunctie een belangrijkere rol bij het maken van strategische keuzes dan marge. Daarnaast is het voor ziekenhuisdirecties moeilijk om beleid te maken op het aanbod, omdat de arts leidend is in de keuze van de behandeling van de patiënt.

\section{Professionalisering (financieel) toezicht}

Alle onderzochte casussen laten in de afgelopen periode een professionalisering van het (financieel) toezicht zien. De toezichthouders die voorheen werden benoemd vanwege hun maatschappelijke positie, zijn vervangen door deskundigen uit de ziekenhuiswereld, ondernemers, bedrijfskundigen, juristen en financieel deskundigen. De gesprekspartners zien de gewijzigde samenstelling niet als een direct gevolg van de invoering van DBC's, maar vooral als een gevolg van algemene maatschappelijke 
ontwikkelingen op het gebied van corporate governance. Eén bestuurder merkt op dat de ontwikkeling van DBC's ook een direct gevolg is van een maatschappelijke tendens naar beheersing en verantwoording. In die zin is het verband dat DBC's leiden tot professionalisering van toezicht of dat professionalisering een maatschappelijke tendens is een 'kip en ei' verhaal. De betrokkenheid van de Raad van Toezicht bij strategische doelstellingen is bij alle onderzochte ziekenhuizen aanwezig en de afgelopen periode sterk toegenomen. Ook speelt de toezichthouder een belangrijkere klankbordfunctie waar het gaat om risicoanalyse en risicobeheersing.

\section{Prestatiebeloning}

Geen van de betrokken ziekenhuizen heeft als gevolg van DBC's prestatiebeloning ingevoerd. DBC's herstellen weliswaar de relatie tussen de (tijds)inspanning en het honorarium voor de medische specialist op basis van een door de Nederlandse Zorgautoriteit vastgesteld uurtarief, maar in 2007 werd het honorarium nog grotendeels (gemiddeld $90 \%$ ) bepaald door middel van het op jaarbudgetten gebaseerde verrichtingen-/lumpsumsysteem van het A-segment. Het onderzoek maakt wel duidelijk dat specialisten gevoelig zijn voor prestatiebeloning: extra beloning zal in hun opinie leiden tot extra inzet en waar mogelijk ook efficiënter werken. Verschillende geïnterviewden citeren dat uit onderzoek blijkt dat in België twee keer zoveel pacemakers worden geplaatst als in Nederland. Deze behandeling is in België voor de arts financieel zeer aantrekkelijk en in Nederland niet. Eén van de geïnterviewde artsen geeft hierbij aan dat binnen de grenzen van hetgeen medisch verantwoord en medisch noodzakelijk is een zekere ruimte bestaat, die beïnvloed kan worden door de beloningsstructuur voor artsen.

\section{Financial control}

Meer dan DBC's hebben generieke budgetkortingen en tegenvallende financiële resultaten ziekenhuizen aangezet tot meer sturing op financiële performance. De onderzochte ziekenhuizen baseren hun planningen controlcyclus nog op de oude functionele bekostigingparameters. Een extra besparing van twee procent wordt op de klassieke wijze gerealiseerd door verlaging van het interne budget. Financieel bewustzijn is beperkt tot de managementlaag en nauwelijks doorgedrongen tot op de werkvloer. De oorzaak voor het ontbreken van een verband tussen invoering van DBC's en verschuiving van medische control naar financial control moet worden gezocht in de positie van de artsen. De beloning van de artsen is onafhankelijk van de kosten van het ziekenhuis, terwijl zij wel de aard en duur van de behandeling van de patiënt bepalen. Dit wordt pas anders als de lumpsumfinanciering wordt afgeschaft, het honorarium van de arts onderdeel vormt van de DBC en volledige bekostiging op basis van DBC's plaatsvindt.

\section{Nieuwe managementinformatiesystemen}

Een groot voordeel van DBC's is de mogelijkheid om behandelingen procesmatig te benaderen en een kostprijs te berekenen. Ook is inzichtelijk te maken op welke momenten in de behandelingen de meeste kosten worden gemaakt. De relevantie van managementinformatie is daarnaast als gevolg van toegenomen financiële risico's sterk toegenomen. De complexiteit van DBC's vraagt echter veel van de in ziekenhuizen gehanteerde ICT-systemen. Zij maken daarom veel gebruik van data-analyses op bestaande registraties, al dan niet uitgevoerd door externe bureaus. Op den duur zullen ziekenhuizen net als commerciële bedrijven willen beschikken over realtime informatie, waarvoor investeringen in hard- en software vereist zijn. Eén van de onderzochte ziekenhuizen geeft expliciet aan dat DBC's direct hebben bijgedragen aan een forse investering in ICT.

\section{Transparante nota's}

De invoering van DBC's leidt in deze casussen voor patiënten niet tot beter inzicht in de nota's. Volgens de betrokken experts zijn de nota's over het algemeen niet beter controleerbaar geworden, terwijl beter inzicht en controleerbaarheid wel aanleidingen vormden voor de invoering van DBC's. Theoretisch vormt een $\mathrm{DBC}$ immers de dienst die een patiënt afneemt van het ziekenhuis. In plaats van verschillende nota's van specialisten, ziekenhuis en ondersteunende specialismen wordt in de DBC-systematiek een gezamenlijke nota verzonden. Het gewenste inzicht wordt om twee redenen niet verkregen. Ten eerste bevatten de nota's naast essentiële verrichtingen ook opslagen voor niet-essentiële verrichtingen zoals röntgenfoto's. Hierdoor zijn diverse factuurregels voor de klant niet herkenbaar als een deel van de behandeling; sterker nog, dit onderdeel wordt ook gefactureerd aan patiënten voor wie dit niet eens is uitgevoerd. Ten tweede vindt facturatie van DBC's bij chronische ziekten slechts eenmaal per jaar plaats. Door de lange doorlooptijd wordt controle bemoeilijkt. Overigens ziet het grootste deel van de patiënten de nota's niet, omdat deze rechtstreeks aan de zorgverzekeraar verzonden worden.

\section{Inrichting interne controlefunctie}

Bij alle onderzochte ziekenhuizen heeft de invoering 
van $\mathrm{DBC}$ 's, en hiermee gelijktijdig de regeling $\mathrm{AO} / \mathrm{IC}$, geleid tot de aanstelling van een interne controlefunctionaris. Het niveau van de uitgevoerde controles is zeer wisselend, van beginnende risicoanalyses tot gestructureerde, periodieke controles door interne registeraccountants. De interne controlefunctie is in de ziekenhuizen breder opgezet dan vereist volgens het wettelijk kader. De interne controle richt zich op de juistheid en rechtmatigheid van de primaire vastlegging, levert een bijdrage aan de betrouwbaarheid van de DBC-registraties en houdt zich bezig met het analyseren van en adviseren over processen binnen de organisatie.

\section{5}

Bij de invoering van DBC's heeft de wetgever beoogd bij te dragen aan transparantere en beter beheersbare ziekenhuiskosten, terwijl ook het zorgaanbod beter op de zorgvraag zou moeten worden afgestemd. In dit onderzoek hebben wij ons de vraag gesteld of de invoering van bekostiging op basis van DBC's al tot de gewenste verbetering van risicobeheersing binnen de Nederlandse ziekenhuizen leidt.

Op een aantal terreinen hebben we (eerste) verbeteringen in de risicobeheersing gezien. Het inzicht dat DBC's geven in het primaire bedrijfsproces en de financiële resultaten, helpt ziekenhuizen om hun strategische doelstelling te realiseren, namelijk patiëntenzorg bieden en continuïteit op lange termijn waarborgen. De overgang van aanbod- naar vraaggestuurde zorg vraagt van het ziekenhuis strategische keuzen en meer bedrijfsmatig werken. We hebben in één geval al een verandering in het zorgaanbod gezien in reactie op een grote vraag in het werkgebied, die ook voor het ziekenhuis financieel aantrekkelijk is.

Risicomanagement als proces staat bij ziekenhuizen nog in de beginfase. Tot op heden is het beleid vooral reactief op wet- en regelgeving. De onderzochte ziekenhuizen hebben nog geen volledig inzicht in de kostprijzen van DBC's, waardoor het doorrekenen van scenario's beperkt plaatsvindt. We zien wel dat bedrijfsmatige analyses als SWOT en business cases worden gebruikt, maar van een gestructureerd programma voor risicomanagement is nog geen sprake, ook al onderkennen de geïnterviewden de mogelijkheden en het nut van DBC's in het kader van risicomanagement wel.

Risicobewaking is de afgelopen periode vooral verbeterd door professionalisering van het toezicht bij ziekenhuizen en door inrichting van een verplichte interne controlefunctie. Deze functie beperkt zich niet alleen tot het controleren van de DBC-registratie, maar levert ook een belangrijke bijdrage aan het denken in processen en risico's. In de loop van de tijd zal deze functie steeds breder ingezet moeten worden en een plaats krijgen in de controle op de betrouwbaarheid van de managementinformatie.

Daartegenover staat dat wij nog geen financieel bewustzijn (en financial control) hebben geconstateerd op de werkvloer; hier overheerst de medisch professionele control nog. Ook is de beloning van medisch specialisten niet gekoppeld aan de DBC's en zijn de nota's voor patiënten nog steeds ondoorgrondelijk.

Alles in overweging nemend, komen wij tot de conclusie dat een procesmatige benadering van risicobeheersing en het structureel inbedden hiervan binnen de ziekenhuisorganisaties nog in de beginfase verkeert. Ziekenhuisbestuurders zien DBC's als beheersingsmiddel, maar erkennen ook de positie van artsen en de onvoorspelbaarheid van de overheid. Beleidsvorming en sturing van de ziekenhuisorganisatie door de Raad van Bestuur verkeren in de overgangsfase van een geplande economie naar marktwerking en verandering is daarin slechts mogelijk met instemming en medewerking van alle partijen. De belangrijkste oorzaak voor het nog niet volledig zichtbaar zijn van de effecten van DBC's is dat in 2007 DBC's voor slechts 10 procent gebruikt zijn voor de bekostiging van ziekenhuizen. De ziekenhuizen geven aan bezig te zijn met het calculeren van kostprijzen in voorbereiding op de groei van het segment met vrije prijsvorming. Als de relevantie van DBC's voor de bekostiging toeneemt, zullen ziekenhuizen hun beheersing nader vormgeven met behulp van DBC's en meer beheersingsmaatregelen treffen. Volledige implementatie van bekostiging op basis van DBC's is voorzien in 2009 en dat lijkt een goed moment om dit onderzoek te herhalen.

\footnotetext{
Literatuur

Aaron, H.J. en W.B. Schwartz (1985), Hospital cost control: a bitter pill to swallow, Harvard Business Review, vol. 63, no. 2, March/April, pp. 160167.

Asselman, F.F. (2007), Ontwerp, implementatie en toepassing van kostprijzen in het AMC, Maandblad voor Accountancy en Bedrijfseconomie, jg. 81, nr. 3, maart, pp. 86-93.

Brancheorganisaties Zorg (2005), Zorgbrede Governancecode, Utrecht; zie: www.nfu.nl/fileadmin/documents/Governance_code_Boz.pdf.

Brandenburg, C.A. (2007), Zorgverzekeraars contracteren ziekenhuizen in een vrije markt, Maandblad voor Accountancy en Bedrijfseconomie, jg. 81, nr. 3, maart, pp. 69-76.

Chua, W.F. en A.Preston (1994), Worrying about accounting in health care, Accounting, Auditing and Accountability Journal, vol. 7, no. 3, pp. 4-17.

Coddington, D.C., L.E. Palmquist en W.V. Trollinger (1985), Strategies for
} 
survival in the hospital industry, Harvard Business Review, vol. 63, no. 3 , May/June, pp. 129-138.

Doolin, B. (2002), Enterprise discourse, professional identity and the organizational control of hospital clinicians, Organization Studies, vol. 23 , no. 3 , pp. 369-391.

Droogsma, J. (2007), Hebben de coso-modellen toegevoegde waarde voor de Rijksoverheid?, Maandblad voor Accountancy en Bedrijfseconomie, jg. 81, nr. 3, maart, pp. 94-107.

Emanuels, J.A. en W.G. de Munnik (2006), Enterprise Risk Management; een risicobeheersingssysteem voor organisaties, Maandblad voor Accountancy en Bedrijfseconomie, jg. 80, nr. 6, juni, pp. 294-299.

Groenewegen, J.P.M. (2007), Transactiekostentheorie en de nieuwe zorgmarkt, Maandblad voor Accountancy en Bedrijfseconomie, jg. 81, nr. 3, maart, pp. 61-68.

Lawrence, S., M. Alam en T. Lowe (1994), The great experiment: financial management reform in the NZ health sector, Accounting, Auditing \& Accountability Journal, vol. 7, no.3, pp. 68-95.

Nederlandse Zorgautoriteit (2007), Administratieve Organisatie en Interne Controle inzake DBC registratie en facturering, Regeling CU/NR100.060; zie: www.nza.nl/7113/12291/100.060.pdf.

Vosselman, E.G.J. (2007), De dokter als economisch medicus: van autonoom arts tot aanbieder op een markt, Maandblad voor Accountancy en Bedrijfseconomie, jg. 81, nr. 3, pp. 54-60.

\section{Noot}

1 SWOT staat voor 'Strengths, Weaknesses, Opportunities \& Threats'. 